\title{
UTILIZATION OF ALUMINA INDUSTRIAL WASTE IN PRODUCTION OF BLENDED CEMENT.
}

\author{
Hagrass, A. A. "; Ibrahim, S. S. ; El-Hosiny, F. I.*; Youssef, S. I. * and Moharam, M. R. ${ }^{\S}$ \\ * Tabbin Institute for Metallurgical Studies, Helwan, Cairo, Egypt. \\ ${ }^{\dagger}$ Central Metallurgical R\&D Institute, Helwan, Cairo, Egypt. \\ ${ }^{*}$ Faculty of Science, Ain Shams University, Cairo, Egypt. \\ $\S$ Faculty of Engineering, Al-Azhar University, Cairo, Egypt.
}

\begin{abstract}
In this study, blended cement pastes are made by different replacements of OPC by alumina (A) using standard water of consistency. The pastes were hydrated for various ages of hydration, up to 28 days. The mechanical and physico-chemical characteristics of the hardened cement pastes were studied and related to the structure of the hardened pastes and the rate of alumina replacement in the blended cement OPC-A pastes. The initial and final setting times of the blended cement pastes were reduced significantly when increasing the amount of partial substitution of alumina in OPC- A cement pastes. It was found that the optimum replacement of OPC by for the improvement of hydraulic properties of blended cement pastes is 5\%. The replacement of alumina in mix A5 causes a marked improvement of the microstructure of pastes. The DSC thermograms and XRD analysis for investigated cement pastes indicated the formation of nearly amorphous calcium silicates hydrates, calcium sulphoaluminate hydrates, calcium aluminate hydrates and Portlandite. The SEM micrographs showed that the partial substitution of OPC by $5 \%$ alumina leads to more dense structure as compared to the neat OPC paste.
\end{abstract}

Keywords: Cement industry, industrial waste, alumina, setting time, compressive strengths, hydration kinetics.

\section{INTRODUCTION}

Increased attention to the environmental impact of ordinary Portland cement (OPC) has prompted researchers to study the optimization of alternative clinker has less construction materials [1]. The use of supplementary cementitious materials in cement industry leads to a significant reduction in $\mathrm{CO}_{2}$ emissions per mass of concrete and, for some additions, it also allows to utilize by-products of industrial manufacturing processes [2].

Crystalline aluminum hydroxide (gibbsite) $\left[\gamma-\mathrm{Al}(\mathrm{OH})_{3}\right]$, is calcined above the temperature of $300^{\circ} \mathrm{C}$ to obtain poorly crystallized phase ore noncrystalline aluminum oxide (alumina) .The reaction of gibbsite to transition alumina:

$$
2 \mathrm{Al}(\mathrm{OH})_{3}(\mathrm{~s}) \rightarrow \mathrm{Al}_{2} \mathrm{O}_{3}(\mathrm{~s})+3 \mathrm{H}_{2} \mathrm{O}(\mathrm{v})[3,4]
$$

The physico-mechanical and fire resistance of cement pastes containing $\mathrm{Al}_{2} \mathrm{O}_{3}$ nanoparticles was studied [5]. The results showed that the water of consistency increases as well as the initial and final setting times accelerated with $\mathrm{Al}_{2} \mathrm{O}_{3}$ content up to 6 mass\%, 
indicating that $\mathrm{Al}_{2} \mathrm{O}_{3}$ enhances the hydration reaction of OPC cement phases. 1 mass $\%$ of $\mathrm{Al}_{2} \mathrm{O}_{3}$ gives a higher value of compressive strength, bulk density, chemically combined water content and gel/space ratio than OPC paste. 1 mass $\% \mathrm{Al}_{2} \mathrm{O}_{3}$ acts as nano-filler which accelerates the rate of hydration. 1 mass $\%$ of $\mathrm{Al}_{2} \mathrm{O}_{3}$ having a good firing resistance than those of other pastes [5]. The effect of elevated temperatures on chemical composition, microstructure and mechanical properties of high strength mortars with nano alumina was investigated [6]. The results showed that nano alumina enhanced compressive strength of samples up to $16 \%$ and improved residual compressive strength. An increase in the relative elastic modulus, higher energy absorption and lower permeability were also observed when $1 \%$ nano alumina was added. The effect of limewater on strength and percentage of water absorption of $\mathrm{Al}_{2} \mathrm{O}_{3}$ nano particles blended concrete has been investigated [7]. Results indicate that $\mathrm{Al}_{2} \mathrm{O}_{3}$ nano particles could improve mechanical and physical properties of the specimens. Frost resistance and mechanical properties of concrete containing nano-silica and nanoalumina are studied [8]. Results showed that the frost resistance of concrete containing nano- $\mathrm{Al}_{2} \mathrm{O}_{3}$ was better than that containing the same amount of nano- $\mathrm{SiO}_{2}$. In addition, compressive strength of normal concrete containingnano- $\mathrm{SiO}_{2}$ was higher than that containing the same amount of nano- $\mathrm{Al}_{2} \mathrm{O}_{3}$. Erdem E. (2003) investigated the ability of using eloxal (waste obtained during the production of aluminum tube and decorative profile) as an additive for rapid hardening of Portland cement [9]. It was observed that, setting times were slightly shortened gradually whereas the flexural and compressive strengths were increased for cements, which was prepared by adding eloxal to Portland cement at various ratios up to $4 \%$ in weight. A slight increase in compressive strength of alumina- OPC paste at the early age of hydration could be determined for addition $\mathrm{Al}_{2} \mathrm{O}_{3}$ up to 3 mass $\%$ of cement. At higher concentration the compressive strength of alumina- OPC paste decreased compared to that of neat cement [10-12].

\section{Experimental Procedures}

The materials used in this study are ordinary Portland cement CEM I 52.5R (OPC) and aluminum hydroxide (industrial waste). OPC was provided by EL Arish Cement Company, North Sinai state, Egypt. Aluminum hydroxide was kindly supplied by Meet Ghammer industrial wastes congregation. Table 1 shows the chemical analysis of aluminum hydroxide. X-ray diffractogram obtained for aluminum hydroxide is shown in figure 1. The results indicate that the all peaks appear wear the gibbsite $\left[\gamma-\mathrm{Al}(\mathrm{OH})_{3}\right]$. The DTA-TG curves of the gibbsite sample heated from room temperature to $1000^{\circ} \mathrm{C}$ are illustrated in figure 2. The first endothermic mass loss located from room temperature to $150^{\circ} \mathrm{C}$ is due to moisture loss. The major endothermic mass loss of the gibbsite sample was observed at $250-600^{\circ} \mathrm{C}$. This endothermic reaction was occurred according to the following equation:

$$
2 \mathrm{Al}(\mathrm{OH})_{3}(\mathrm{~s}) \rightarrow \mathrm{Al}_{2} \mathrm{O}_{3}(\mathrm{~s})+3 \mathrm{H}_{2} \mathrm{O}(\mathrm{v}) \text {. [4] }
$$

This was occurred with weight loss equal $28.55 \%$. This can be attributed to endothermic dehydroxylation (or dehydration) of $\mathrm{Al}(\mathrm{OH})_{3}$ to produce disordered poorly crystallized phase ore noncrystalline aluminum oxide (alumina). 
Table (1): Chemical analysis of aluminum hydroxide.

\begin{tabular}{|l|c|c|c|c|c|c|c|c|c|}
\hline & $\mathrm{Al}_{2} \mathrm{O}_{3}$ & $\mathrm{SiO}_{2}$ & $\mathrm{Na}_{2} \mathrm{O}$ & $\mathrm{Fe}_{2} \mathrm{O}_{3}{ }^{\text {tot }}$ & $\mathrm{SO}_{3}$ & $\mathrm{CaO}$ & $\mathrm{TiO}_{2}$ & $\mathrm{Cr}_{2} \mathrm{O}_{3}$ & $\mathrm{~K}_{2} \mathrm{O}$ \\
\hline Wt., \% & 98.29 & 0.72 & 0.39 & 0.25 & 0.03 & 0.16 & 0.10 & 0.016 & 0.04 \\
\hline
\end{tabular}

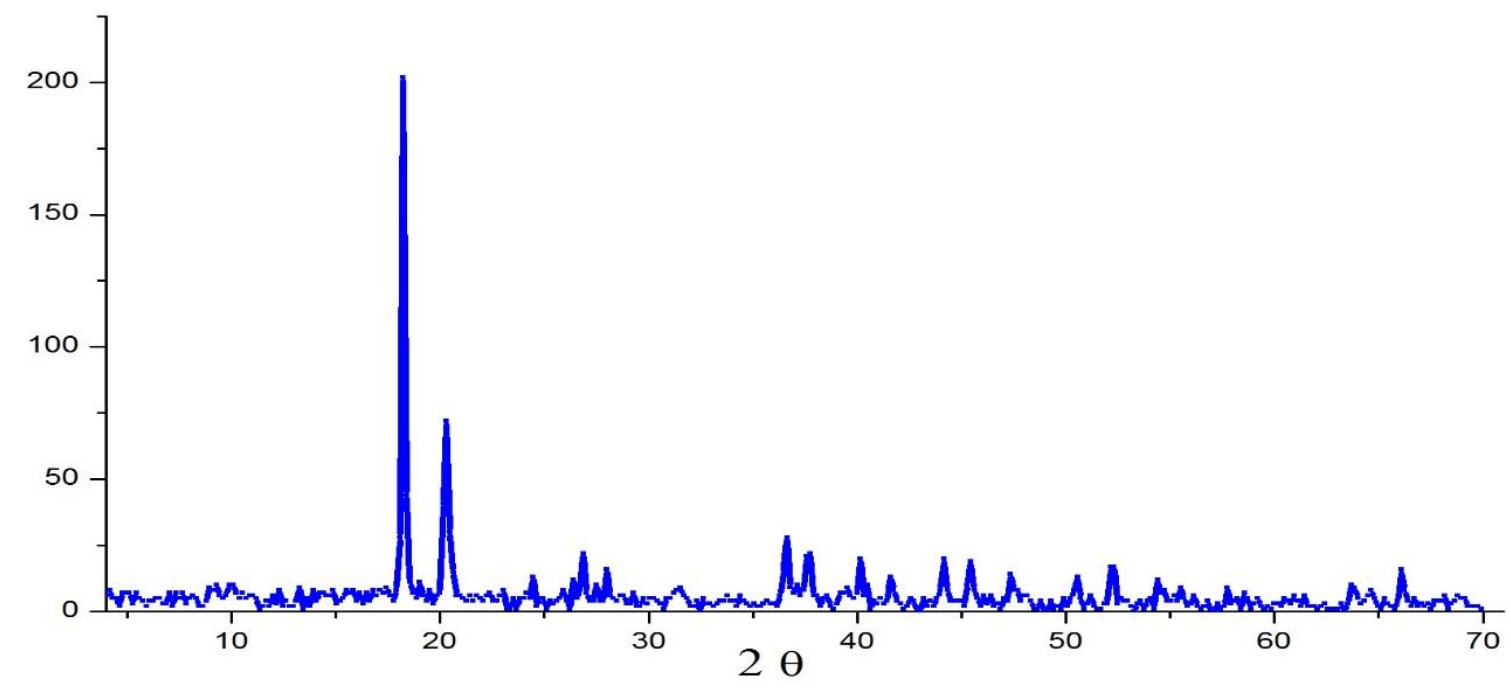

Fig. 1: XRD of aluminum hydroxide.

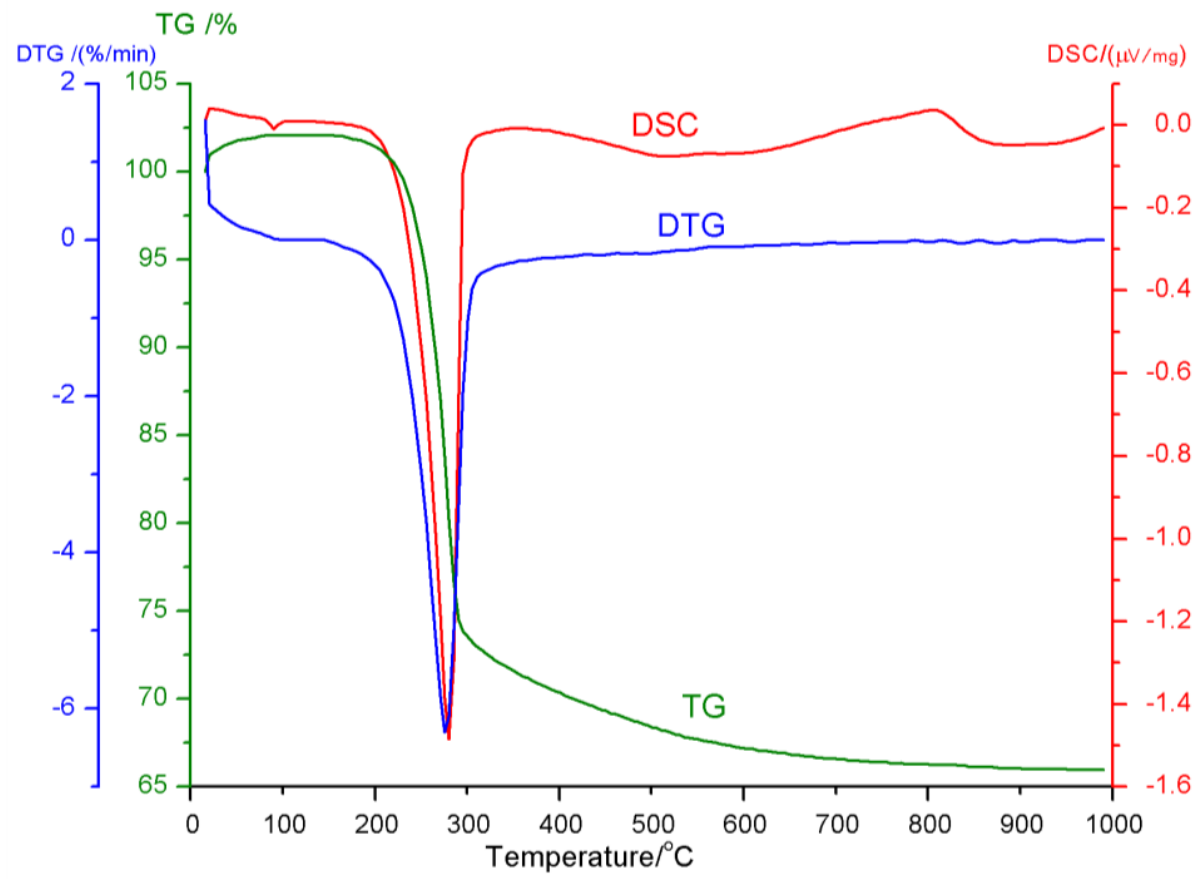

Fig. 2: Thermal analysis of aluminum hydroxide.

DTA was carried out using "NETZSCH STA 409 C/CD", to determine the optimum range of calcination temperatures that will produce amorphous alumina. Aluminum hydroxide was calcined at different temperatures conditioned from $300^{\circ} \mathrm{C}$ to $900^{\circ} \mathrm{C}$ in a laboratory electric furnace for four hours, to obtain amorphous alumina. XRD analysis was conducted by using XR diffractometer, model Bruker axs, D8 Advance to 
determine the mineralogical composition of alumina. Scanning electron microscope, (SEM), has been used to study the morphology and microstructure of the minerals used in this study. For SEM examination, freshly fractured specimens were coated with a thin film of gold under vacuum evaporator with cathode rays. FEI Inspect S50 Scanning electron microscope was used in this investigation. Series of blend mixtures were prepared from OPC blended with different ratios of alumina as shown in table 2.

Table (2): Percentage composition of the investigated alumina cement blends.

\begin{tabular}{|c|c|c|}
\hline Mix & OPC & A \\
\hline A0 & 100 & 0 \\
\hline A5 & 95 & 5 \\
\hline A10 & 90 & 10 \\
\hline
\end{tabular}

Each dry mixture was mechanically stirred for 3 hours in porcelain mixer to attain complete homogeneity, and then kept airtight containers for further investigation. The water requirements of the cementitious mixtures (normal water of consistency) as well as initial and final setting times were measured by Vicat apparatus according to ASTM C 187,191[13]. The OPC and blended cement dry mixtures were carried out with the required water of consistency. Each dry mixture was mixed with water for about 3 minutes. After mixing, the resulting pastes were molded into cubic specimens $\left(2.54 \times 2.54 \times 2.54 \mathrm{~cm}^{3}\right)$ by using stainless steel cubic moulds. Immediately after molding, the moulds were cured at about $100 \%$ relative humidity at room temperature for the first 24 hours in order to attain the final setting of the specimens [14]. After $24 \mathrm{hrs}$, the hardened cement pastes were then removed from the moulds and cured under tab water. The applied curing hydration time intervals were 3, 7, 14 and 28 days. The stopping of hydration process was performed on the crushed cubic specimens after the compressive strength determination. The stopping solution was composed of methyl alcohol and acetone (1:1 by volume) [15]. Finally, the powdered samples were dried at $80^{\circ} \mathrm{C}$ for three hours in $\mathrm{CO}_{2}$ - free atmosphere and maintained in a desiccator for further investigation. Kinetics of hydration process was studied from the determination of chemically-combined water $(\mathrm{CW}, \%)$ and free lime $(\mathrm{CaO}, \%)$ contents for the hardened specimens at different intervals time of hydration [14]. X-ray diffraction technique was carried on some selected hydrated and dried OPC-Alumina cement pastes. The thermal behavior of the hydrated specimens of different OPC-Alumina mixes was tested by DSC technique using DSC-50 instrument from Shimadza (Japan) with a heating rate of $10^{\circ} \mathrm{C} / \mathrm{min}$.

\section{RESULTS AND DISCUSSIONS}

\subsection{The Setting Time Determination of the Hardened Blend OPC Pastes Containing Alumina}

The initial and final setting times of neat OPC (A0) and various blended cement pastes (A5 andA10) are shown in figure 3. It indicates that both initial and final setting times of the blended cement pastes were reduced significantly when increasing the amount of partial substitution of alumina in OPC- A cement pastes. This is attributed to the rapidly formed hydration product of calcium aluminate hydrate $(\mathrm{CAH})[16]$. 


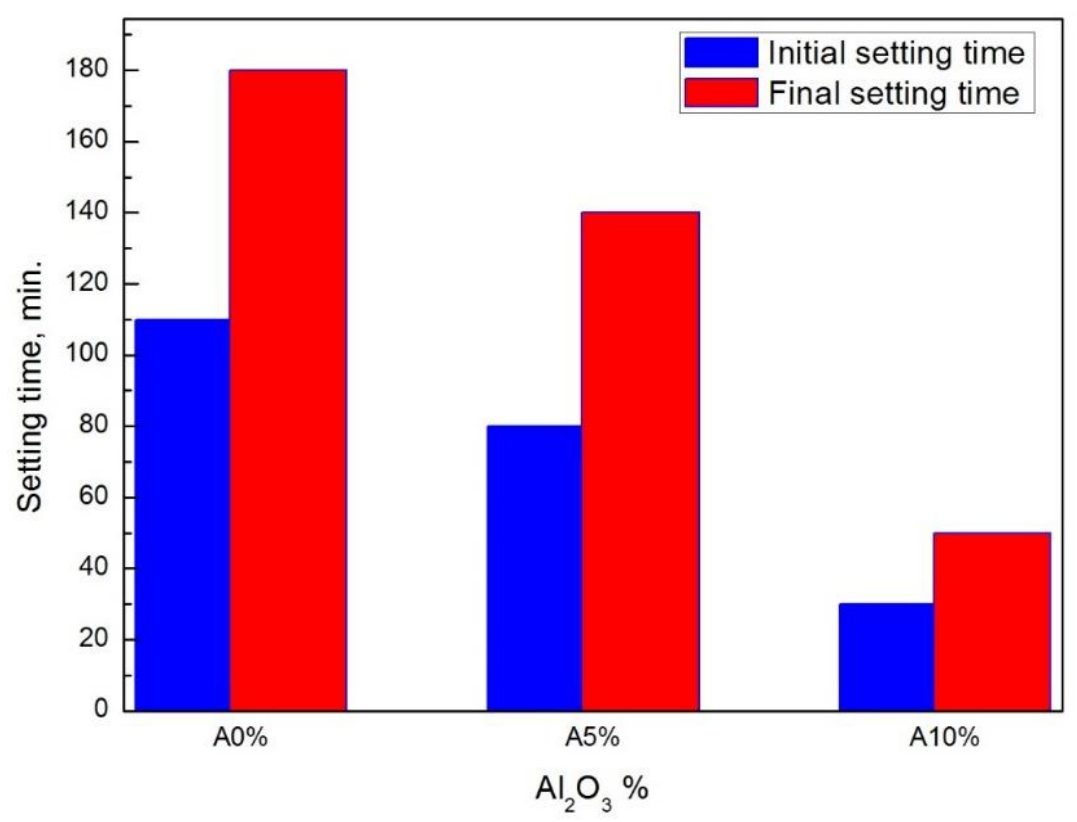

Fig. 3: Vicat initial and final setting times at standard water of consistency obtained for various blended cement pastes containing alumina according to ASTM C 191.

3.2. Compressive Strength Measures and Hydration Kinetics of Neat OPC and OPC-A Hardened Blended Pastes

The results of compressive strength of neat and blended cement pastes containing 5 and $10 \%$ alumina by the weight percent are represented in figure 4.

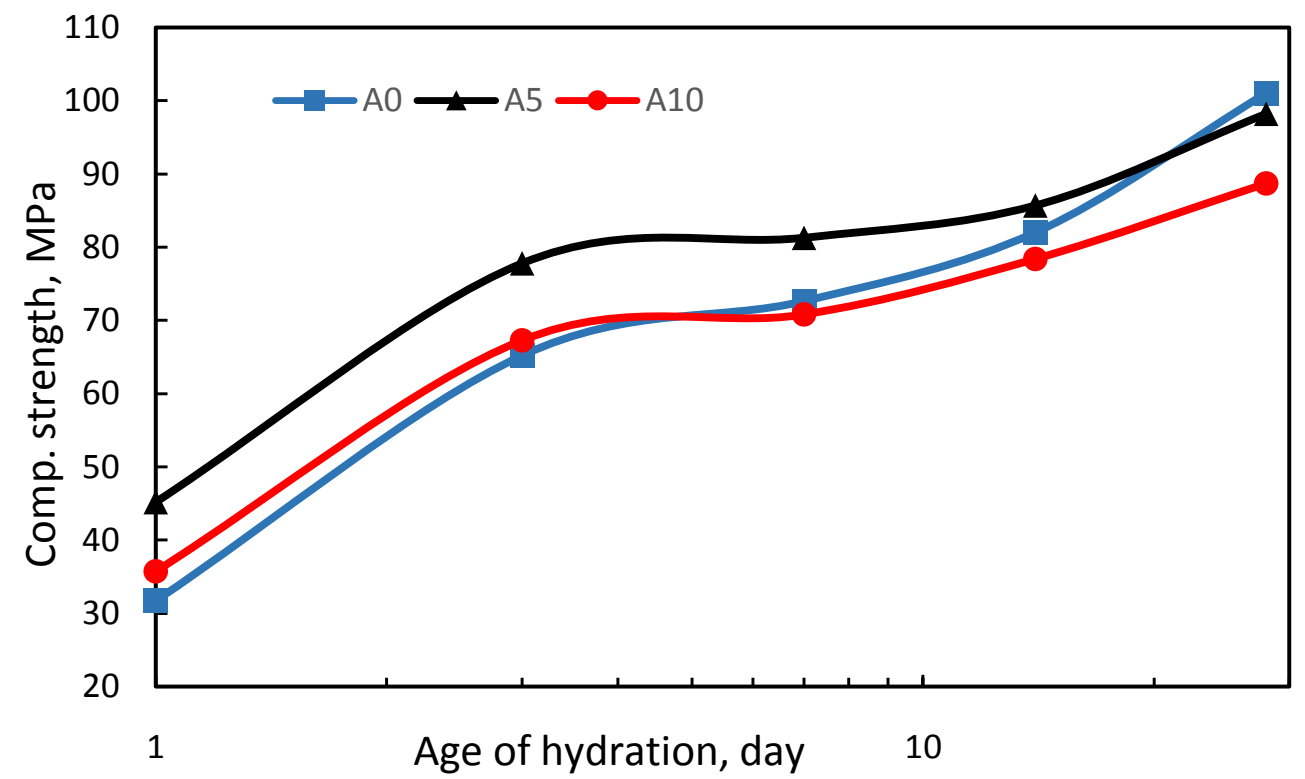

Fig. 4: The results of compressive strength versus age of hydration for neat OPC and various OPC-A hardened pastes. 
The partial substitution of OPC by various amounts of alumina of $5 \%$ and $10 \%$ and hydrated for $1,3,7,14$ and 28 days lead to increase the compressive strength values than those obtained in case of the neat OPC paste (A0) during early ages of hydration1 and 3 days. However, the blended cement pastes showed slight lower or nearly comparable compressive strength values to the neat OPC pastes at later ages of hydration (at 7 and 28 days) it impaired the later age compressive strength. This increased in compressive strength values attributed to the accelerate hydration reaction of cement, and the decreased compressive strength values at the later age attributed to the change of hydration products from acicular crystal shape (ettringite) to hexagonal tabular crystal shape $\left(\mathrm{C}_{4} \mathrm{AH}_{19}\right.$ and $\left.\mathrm{C}_{2} \mathrm{AH}_{8}\right)$, and the hindered hydration process of calcium silica phase [17]. The decreasing in the compressive strength values of the hardened pastes made of mix A10 having high percentages of alumina may be attributed to the presence of residual (unreacted) amounts of alumina, which act as filler in the hardened OPC-A pastes. [13]

Figure 5 illustrates that the results of chemically combined water content versus the ages of hydrations for all of investigated pastes $(\mathrm{A} 0-\mathrm{A} 10)$. The results indicate a fast hydration reaction takes place from the time of mixing up to 1 day of hydration; followed by an acceleration stage of hydration up to 3 days of hydration. After that, the initially formed hydration products shield the cement grains leading to a slower rate of hydration reaction from 7-14 days of hydration. This is followed by a gradual increase in the rate of hydration up to the final stages of hydration (28 days) for A0 and A5. The chemically combined water value of mix A10 decrease at final stage of hydration due to presence of unreacted amounts of alumina and / or the crystallization of initially formed hydrates.

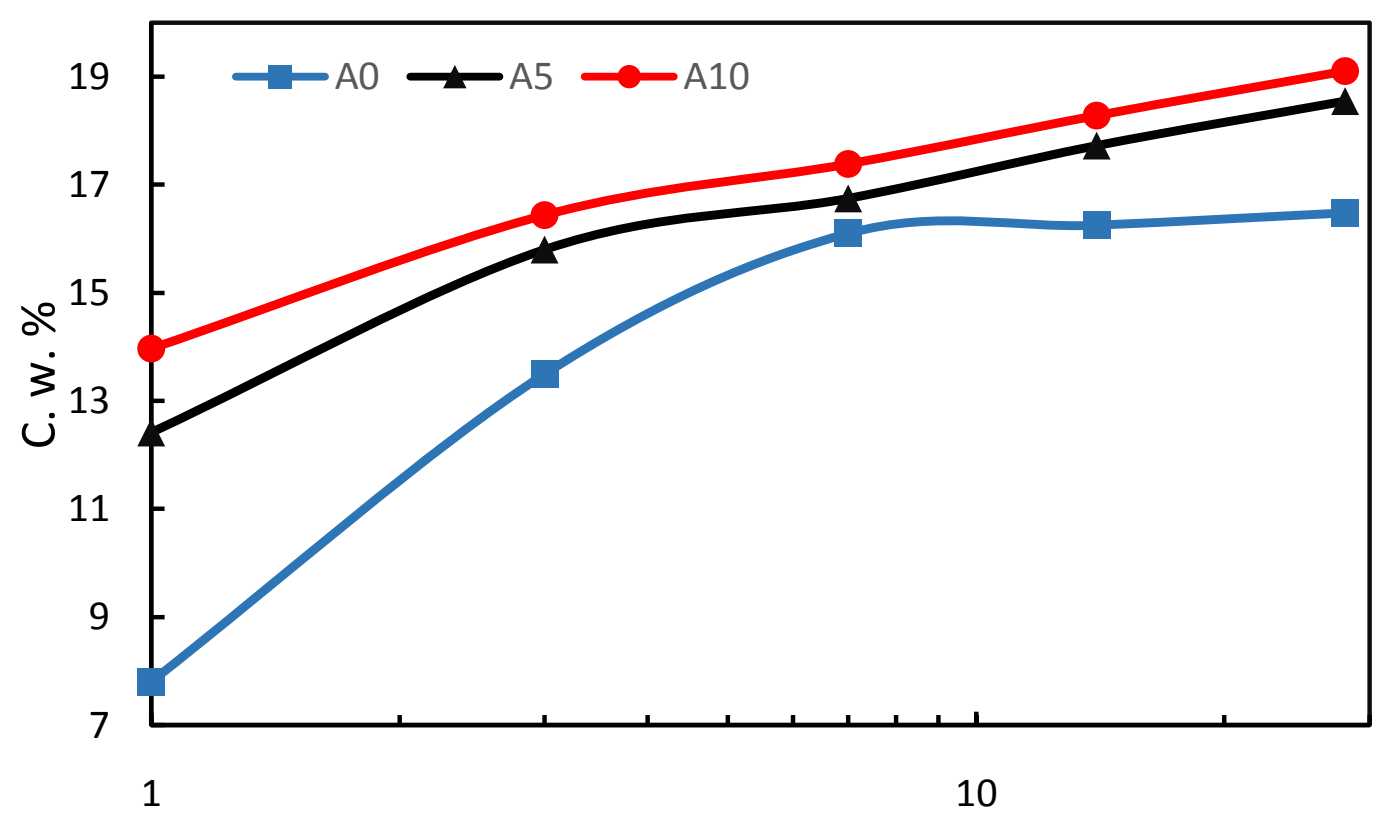

Age of hydration, day

Fig. 5: The results of chemically combined water content, versus age of hydration for neat OPC and various OPC-A hardened pastes. 
Figure 6 represents the results of free lime content versus age of hydration for all investigated cement specimens (mixes A0 - A10). The free lime content increases continuously with increasing age of hydration for the neat OPC paste indicating the continuous liberation of free lime $(\mathrm{CH})$ from the hydration of OPC. On the other hand, the observed free lime contents for all OPC-A hardened pastes is a net result of two opposite effect, first increase in the amount of free lime which liberated from hydration of Portland cement while the second effect is the consumption of the liberated lime via its pozzolanic reaction with alumina[18]. Therefore, the results indicate that the free lime contents obtained for all admixed OPC-A pastes are lower than those of the neat OPC paste. In addition, as the percentage of alumina replacement increases, the free lime content decreases because of the consumption by the pozzolanic reaction. Obviously, the pozzolanic cement paste having the highest alumina content (A10) has the lowest free lime contents at all ages of hydration; this is due to the marked consumption of free lime by alumina because of the pozzolanic reaction [18].

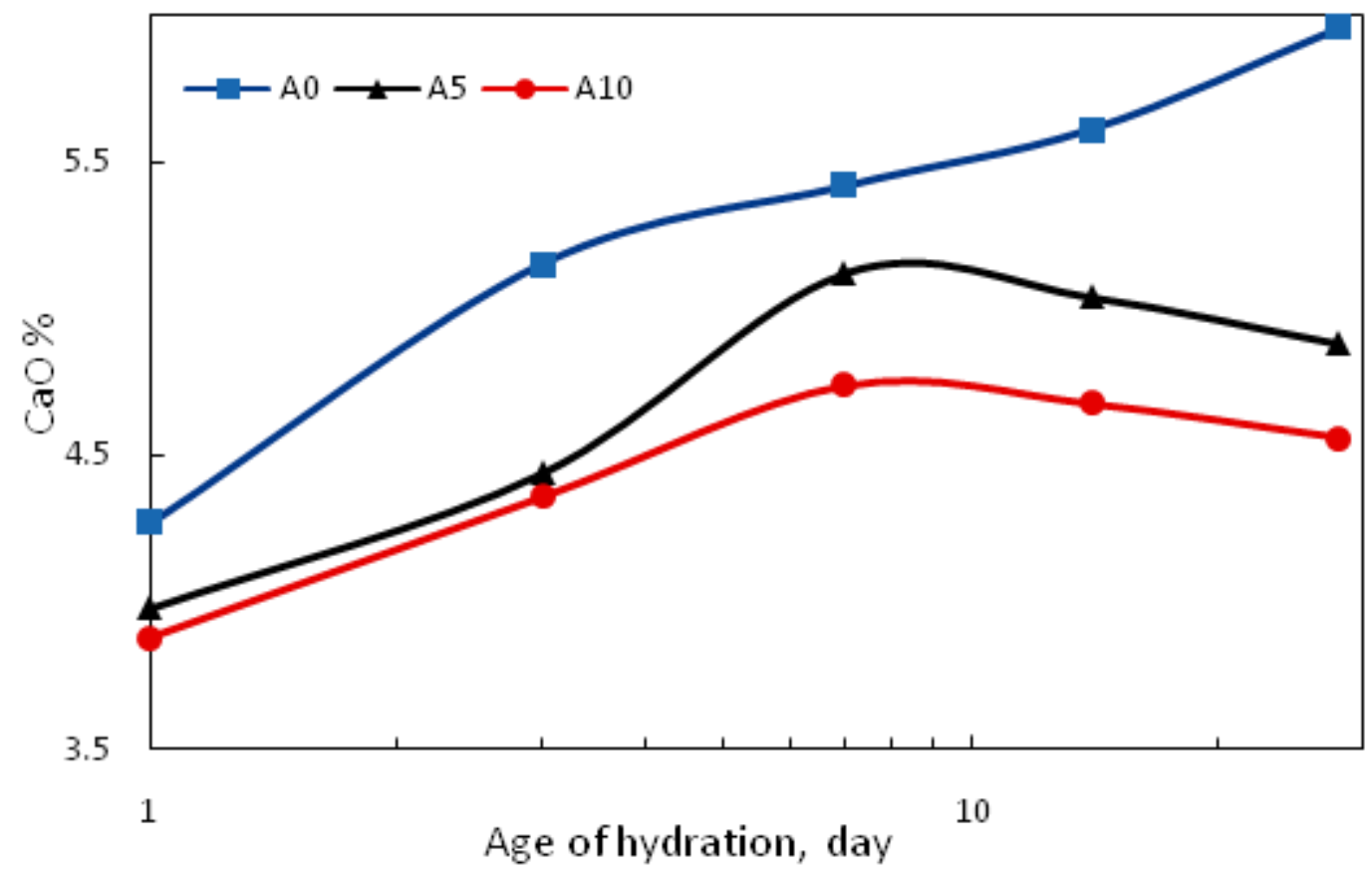

Fig. 6: The results of free lime content versus age of hydration for neat OPC and various OPC-A hardened pastes.

\subsection{Thermogravimetric (TG), Differential Scanning Calorimetry (DSC) and Differential Thermogravimetric Analyses (DTA).}

The TG, DSC and DTG thermograms of the hardened pastes made of neat OPC (A0) and blended pastes made of 95\% OPC and 5\% alumina (A5) after 1, 14 and 28 days of hydration at room temperature are shown in figures 7.1 and 7.2, respectively.

The thermograms of TG, DSC and DTG obtained for the neat OPC paste (blank) are shown in figures 7.1a, 7.1b and 7.1c, after hydration for 1,14 and 28 days, respectively. The results in figures 7.1a, b and c indicate the presence of three endothermic located at $60-130^{\circ} \mathrm{C}$ is mainly due to the dehydration of the calcium sulphoaluminate hydrates as well as the amorphous and microcrystalline pastes of calcium silicate hydrates (CSH). 
The weak endotherm appeared at temperature below $100^{\circ} \mathrm{C}$ is attributed to the removal of free water content. The intensity of these endothermic peaks increases with the increase of hydration time up to 28 days; this is due to the excessive formation of larger amounts and/ or the latter crystallization of CSH with increasing age of the main hydration products of OPC.

In general, the endotherm peaks appeared after $100^{\circ} \mathrm{C}$ up to $130^{\circ} \mathrm{C}$ are mainly due to the dehydration of interlayer calcium silicate hydrates $(\mathrm{CSH})$, calcium aluminate hydrates $(\mathrm{CAH})$ and calcium sulphoaluminate hydrates [19]. The second peak located at 410$450^{\circ} \mathrm{C}$, which appeared in figures $7.1 \mathrm{a}, 7.1 \mathrm{~b}$ and $7.1 \mathrm{c}$, for the neat OPC paste (blank) after 1, 14 and 28 days, respectively, which represents the major weight loss; this is mainly related to the decomposition of calcium hydroxide $(\mathrm{CH})$ liberated from the hydration of OPC. The intensity of these endothermic peaks (DSC and DTG) increases with increasing age of hydration from 1 to 28 days of hydration; this increase is attributed to the increase in the amount of liberated free $\mathrm{Ca}(\mathrm{OH})_{2}$ during OPC hydration. The area of this endothermic peaks increases with increasing age of hydration from 1 to 28 days; these indications are due to increase in amount of $\mathrm{CH}$; this results; is in agreement with the results of volumetric determination of free lime content. Finally, the third endothermic peaks of TG, DSC and DTG located at 660$720^{\circ} \mathrm{C}$ in figures $7.1 \mathrm{a}, 7.1 \mathrm{~b}$ and $7.1 \mathrm{c}$ is due to decomposition of calcium carbonate [20]. The area and intensity of this endothermic peak decrease with increasing age of hydration from 1 to 28 days. This result is attributed to the reaction of $\mathrm{CO}_{2}$ in the moisture with $\mathrm{CaCO}_{3}$ to form $\mathrm{Ca}\left(\mathrm{HCO}_{3}\right)_{2}$ and/ or the increase in the degree of crystallinity of hydration products. This indication is accounted for the degree of carbonation of the hardened pastes.

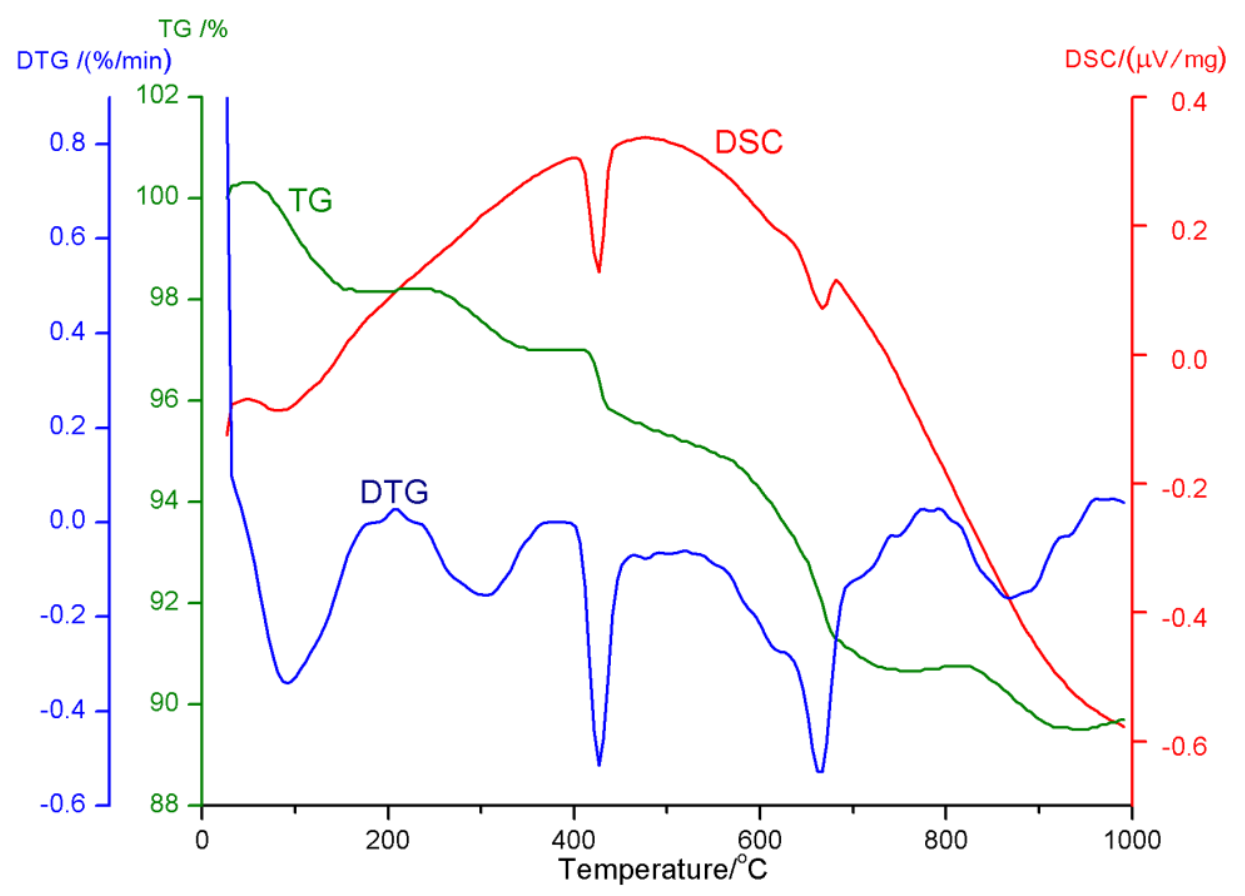

Fig. 7.1a: The TG, DSC and DTG thermograms of the hardened neat OPC after 1 day. 


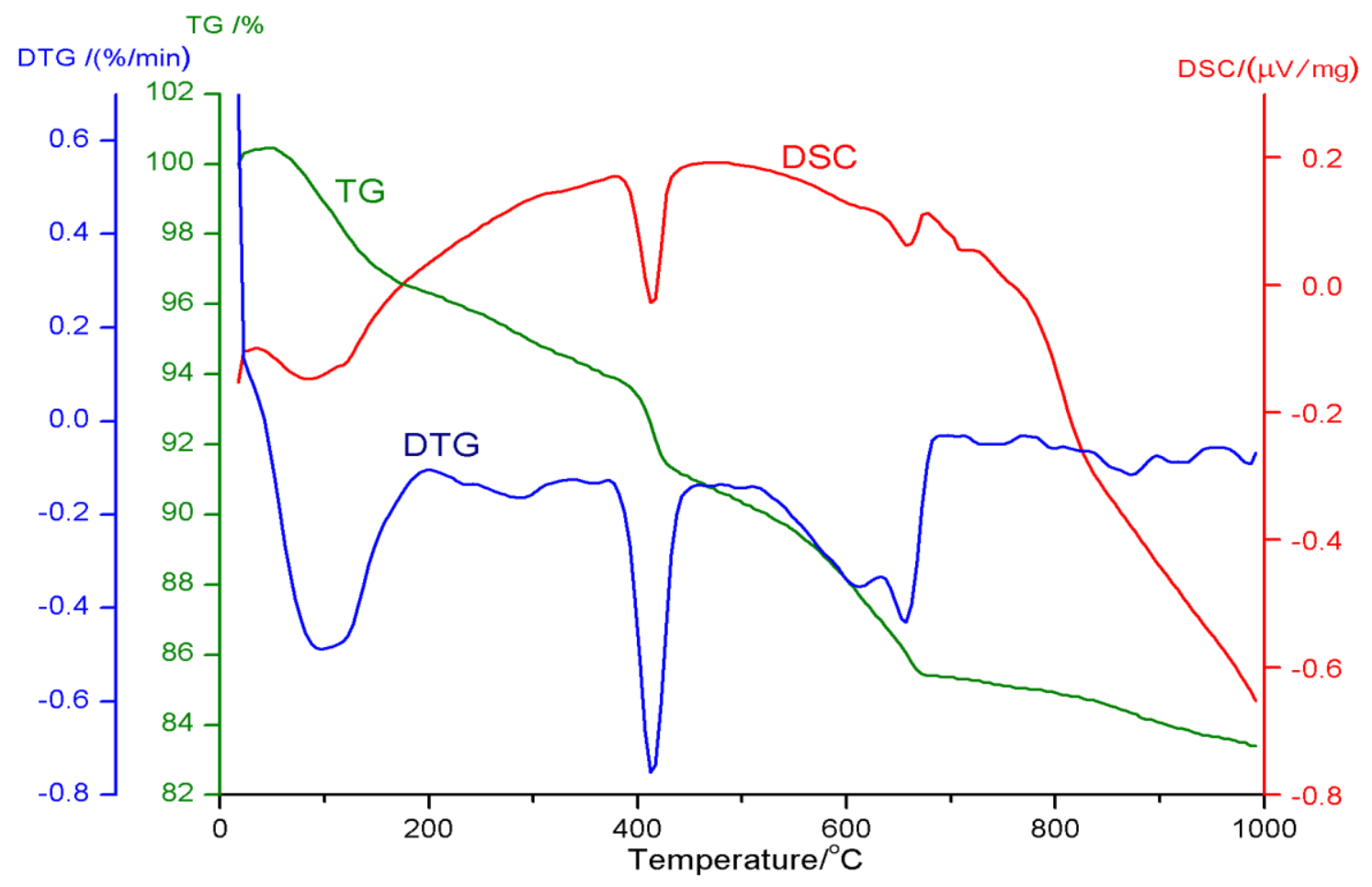

Fig. 7.1b: The TG, DSC and DTG thermograms of the hardened neat OPC after 14 days.

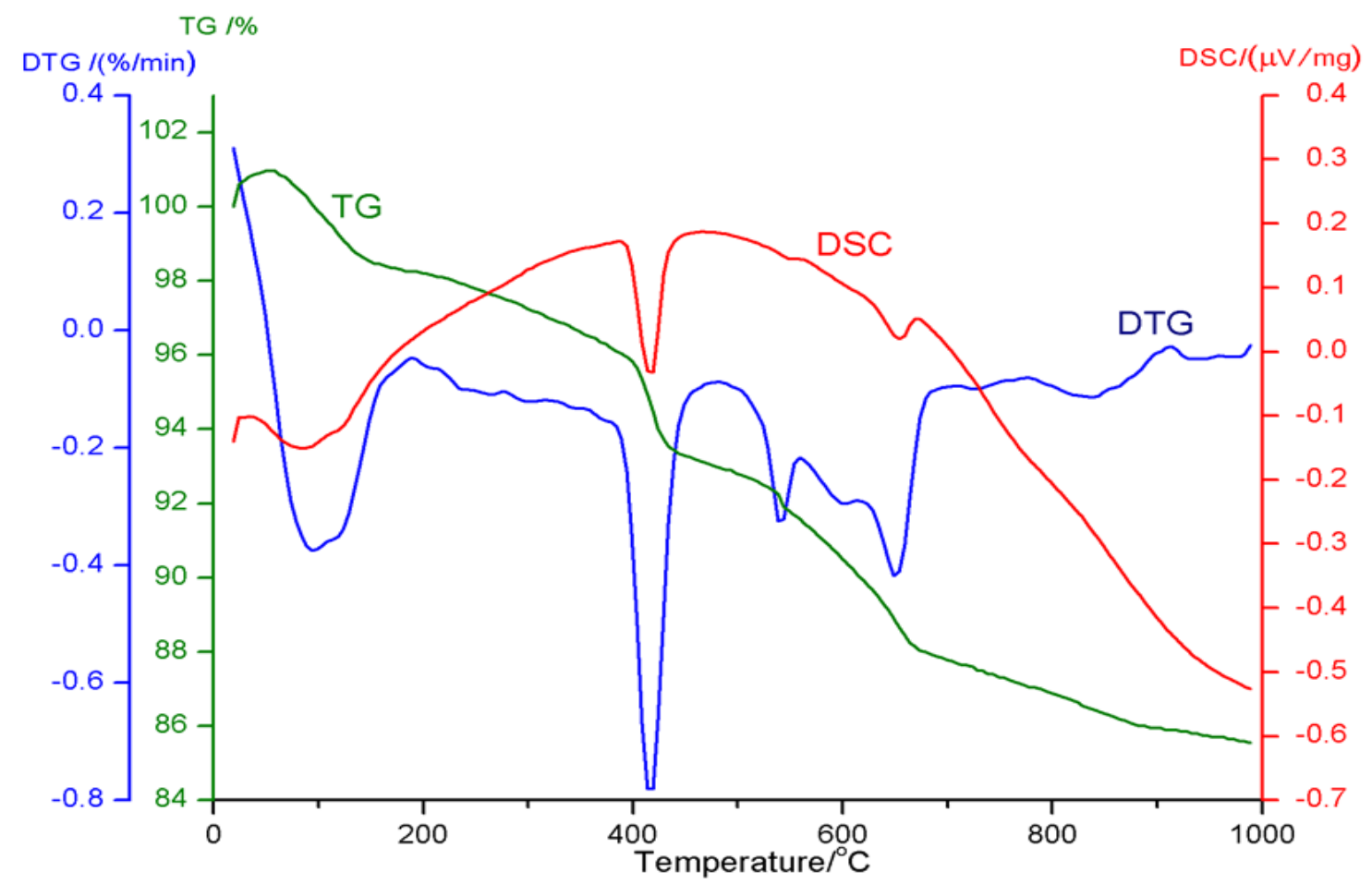

Fig. 7.1c: The TG, DSC and DTG thermograms of the hardened neat OPC after 28 days. 
The thermograms of TG, DSC and DTG obtained for the blended cement pastes made of $95 \%$ OPC and 5\% A are shown in figures 7.2a, 7.2b and 7.2c hydrated for 1,14 and 28 days, respectively. The first endotherm peak located at $166-200^{\circ} \mathrm{C}$ is due to the decomposition of calcium aluminate hydrates $\left(\mathrm{CAH}, \mathrm{C}_{4} \mathrm{AH}_{13}\right)$ or stratlingite $\left(\mathrm{C}_{2} \mathrm{ASH}_{8}\right)$ which overlapped with calcium sulphoaluminate hydrates (ettringite and mono sulphate hydrates). The intensity of these endothermic peaks increases with the increase of hydration time up to 28 days; this is due to the excessive formation of larger amounts of calcium aluminate hydrates $(\mathrm{CAH})$ and stratlingite $\left(\mathrm{C}_{2} \mathrm{ASH}_{8}\right)$ with increasing age of hydration of OPC as well as the pozzolanic reaction between the liberation $\mathrm{CH}$ and alumina. The second endotherm peak located at $380-410^{\circ} \mathrm{C}$ is due to the decomposition of hydrogarnet $\left(\mathrm{C}_{3} \mathrm{ASH}_{6}\right)$.

The intensity of these endothermic peaks increases with the increase of hydration time up to 28 days; this is due to the excessive formation of larger amounts of hydrogarnet $\left(\mathrm{C}_{3} \mathrm{ASH}_{6}\right)$ with increasing age of hydration of OPC as well as the pozzolanic reaction between the liberation $\mathrm{CH}$ and alumina. The third endothermic peak located at 580$610^{\circ} \mathrm{C}$, which represents the major weight loss, is mainly related to the decomposition of calcium hydroxide (portlandite). The intensity of this endotherm peak decreases with increasing age of hydration from 1 to 28 days as indicated from the results of figures 7.2a, 7.2b and 7.2c. These results are explained in terms of the decrease in the amount of free calcium hydroxide due to its pozzolanic consumption with alumina. The fourth endotherm located at $650-680^{\circ} \mathrm{C}$ related to the decomposition of calcium carbonate with different degrees of crystallinity; these endothermic peaks are accounted for the degree of carbonation of the hardened pastes. In general, the endothermic peaks appeared in the thermograms obtained for hardened OPC- A pastes showed that the pozzolanic reaction between alumina and free $\mathrm{Ca}(\mathrm{OH})_{2}$ leads to a notable decrease in their intensities. In addition, the endotherm appeared at $650-680^{\circ} \mathrm{C}$ cover a wider range of temperature; this is due to the differences in the degree of crystallization of the formed $\mathrm{CaCO}_{3}$.

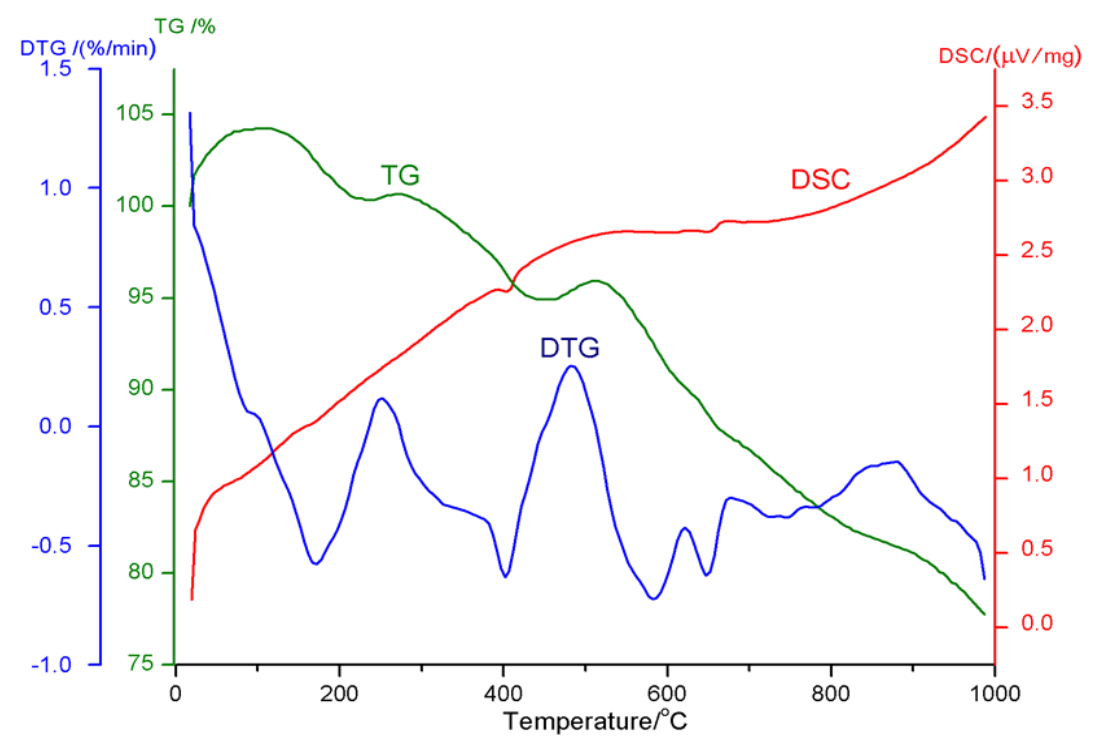

Fig. 7.2a: The TG, DSC and DTG thermograms of the hardened OPC-A paste made of mix A5 after 1 day. 


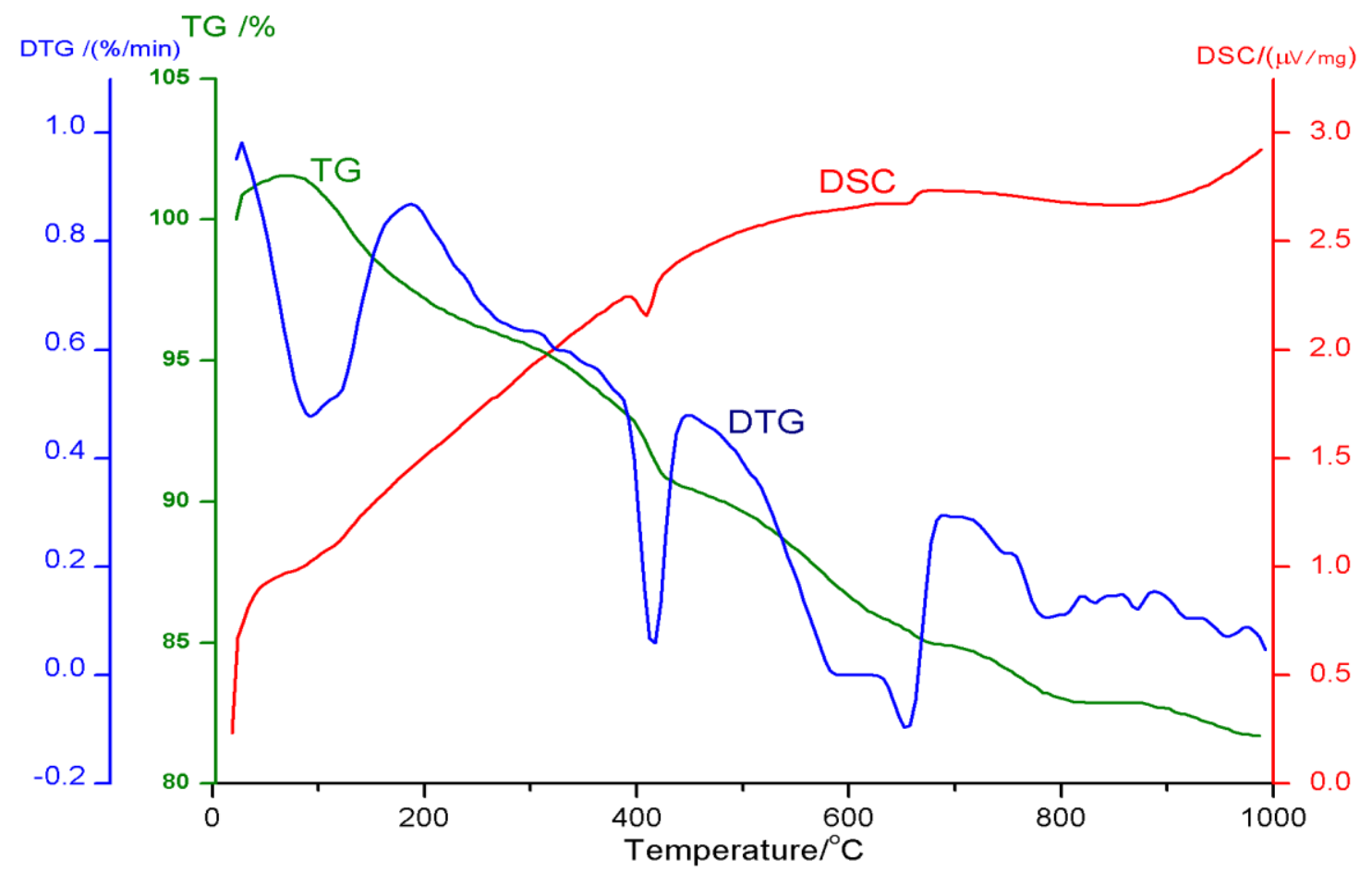

Fig. 7.2b: The TG, DSC and DTG thermograms of the hardened OPC-A paste made of mix A5 after 14 day.

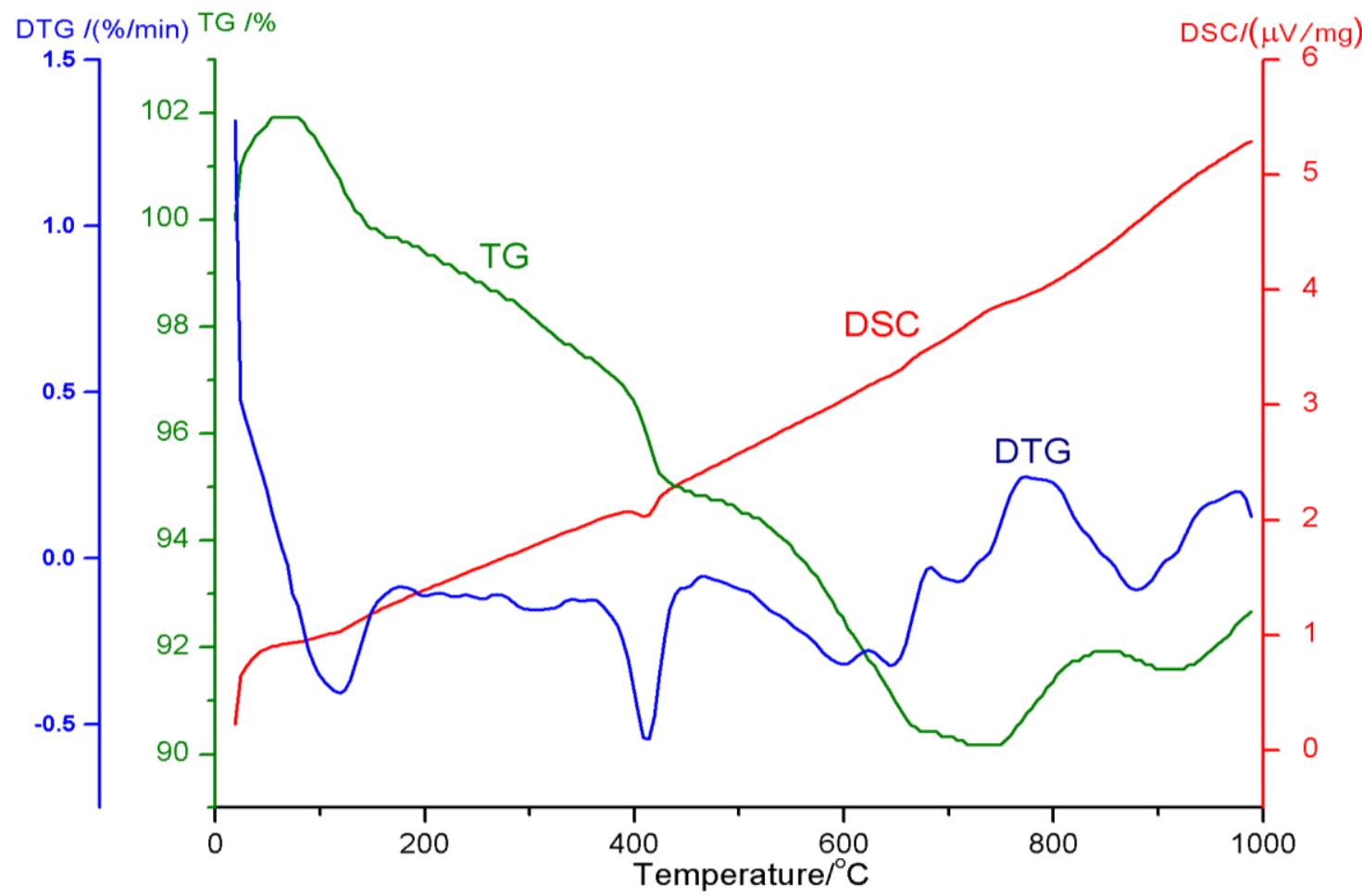

Fig. 7.2c: The TG, DSC and DTG thermograms of the hardened OPC-A paste made of mix A5 after 28 day. 


\subsection{X-ray Diffraction (XRD) Analysis}

X-ray diffractograms obtained for the hardened cement pastes made of neat OPC (A0) and mix A5 containing 5\% alumina after 28 days of hydration are shown in figure 8. The results indicate that the distinct phases identified for the formed hydration products.

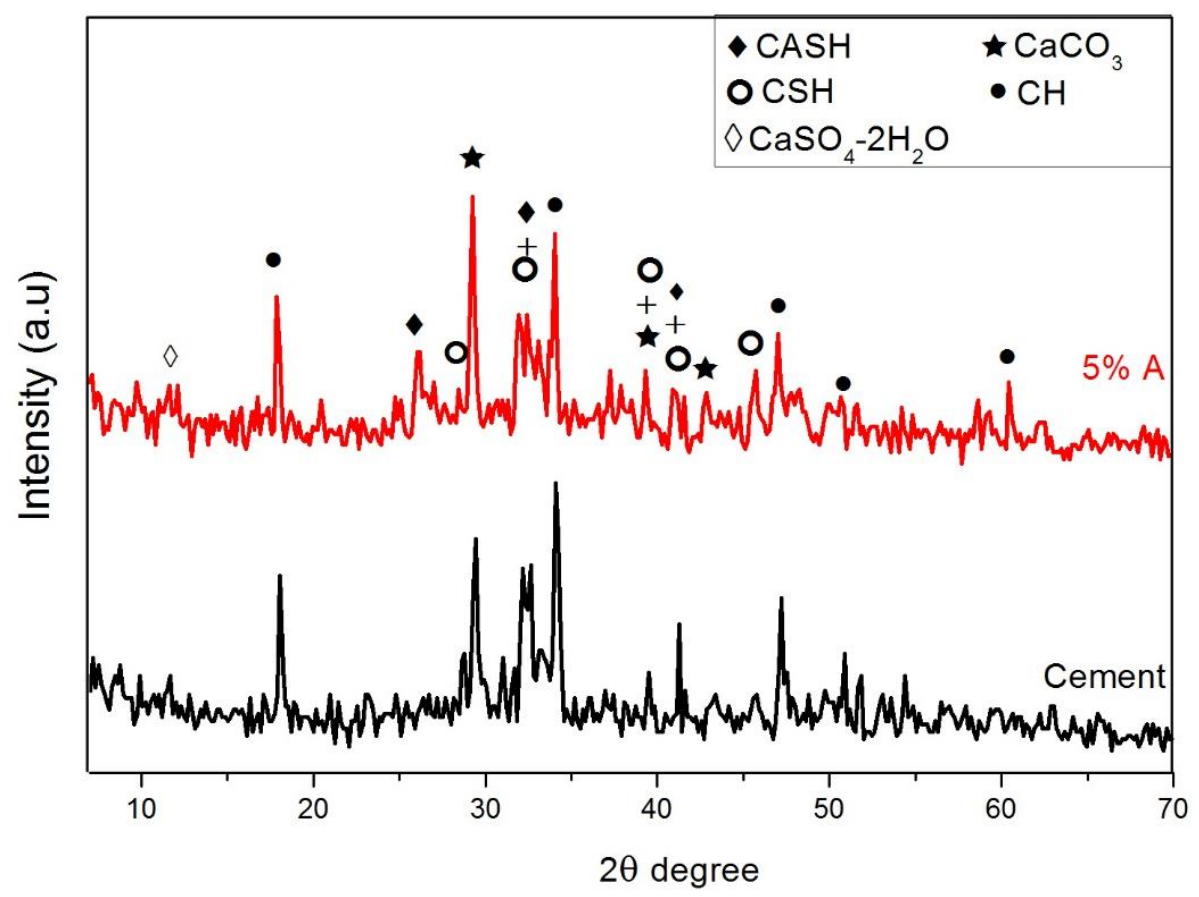

Fig. 8: XRD Patterns for the hardened cement pastes of neat OPC (A0) and OPC containing $5 \%$ alumina (A5) after 28 days of hydration.

The peaks characterizing tricalcium aluminate $\left(\mathrm{C}_{3} \mathrm{~A}\right)$ were not detected as expected due to the fast rate of hydration and its reactivity with gypsum with the formation of ettringite $\left(\mathrm{C}_{3} \mathrm{~A} .3 \mathrm{CaSO}_{4} .32 \mathrm{H}_{2} \mathrm{O}\right)$ which is transformed to mono-sulphate hydrate $\left(\mathrm{C}_{3} \mathrm{~A} . \mathrm{CaSO}_{4} .12 \mathrm{H}_{2} \mathrm{O}\right)$ during the early stages of hydration and overlapped with the peaks of unhydrated silicate phases and hydrated calcium silicates. The calcium hydroxide phase formed as a result of hydration of anhydrous calcium silicates in OPC clinker, could be distinguished, as well as the calcium silicate hydrates, $\mathrm{CSH}$ (I) and (II), as the main hydration products, figure 8 .

The main hydration products of hardened OPC paste blended with $5 \%$ alumina (mix A5), are the nearly amorphous and microcrystalline calcium aluminate hydrates (CAH), calcium hydroxide $(\mathrm{CH})$ and calcium aluminosilicate hydrates $(\mathrm{CASH})$. In conclusion, the intensity of $\mathrm{CH}$ peaks of blended cement paste containing 5\% alumina (mix A5) is lower than that in case of neat OPC (A0); this due to the consumption of $\mathrm{CH}$ with alumina (pozzolanic reaction). Meanwhile, the intensity of hydration products of calcium silicate hydrates $(\mathrm{CAH})$ and calcium aluminate silicate hydrates $(\mathrm{CASH})$ of mix $\mathrm{A} 5$ is larger than in case of $\mathrm{A} 0$.

\subsection{Scanning Electron Microscopy (SEM)}

The microstructure of the neat OPC paste (A0) hydrated for 28 days is shown in figure 9. The formation of crumpled fibrous particles of tobermorite-like $\mathrm{CSH}$ phases was 
indicated as the dominant hydration products, figure 9. The hexagonal calcium aluminate hydrates and hexagonal calcium hydroxide (portlandite) deposited in the originally water-filled spaces as well as unhydrated cement grains.

The microstructure of the hardened OPC paste blended with 5\% alumina after 28 days of hydration are shown in figure 10. The SEM micrograph indicated the formation of crumpled fibrous particles with dense structure of tobermorite-like CSH phases as the dominant hydration products among the other hydrated phases deposited in the originally water-filled spaces in addition to the presence of unhydrated parts of cement and alumina grains. The crystals of calcium hydroxide $(\mathrm{CH})$ and porosity appeared in paste made of OPC without alumina addition (A0) are relatively disappeared in this paste as a result of pozzolanic reaction with addition of $5 \%$ alumina.
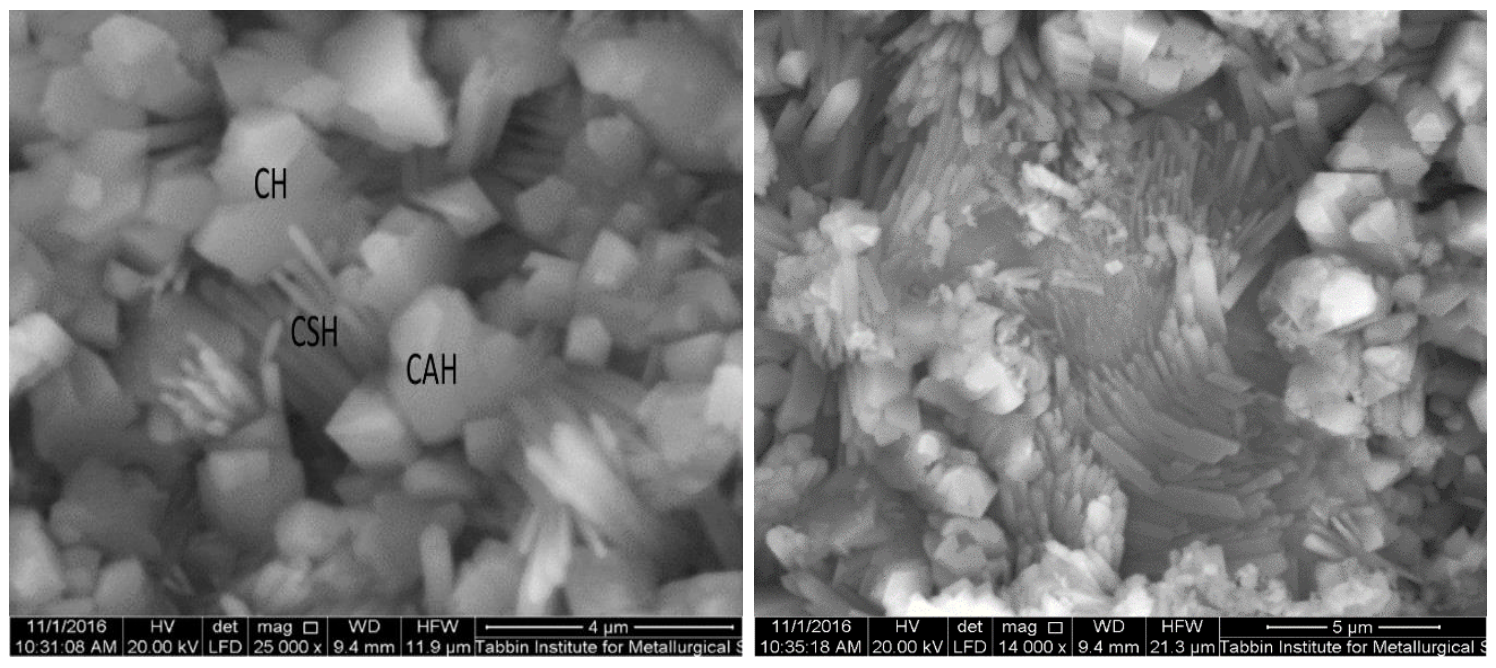

Fig. 9: SEM micrograph for the hardened neat OPC paste (A0) after 28 days of hydration.
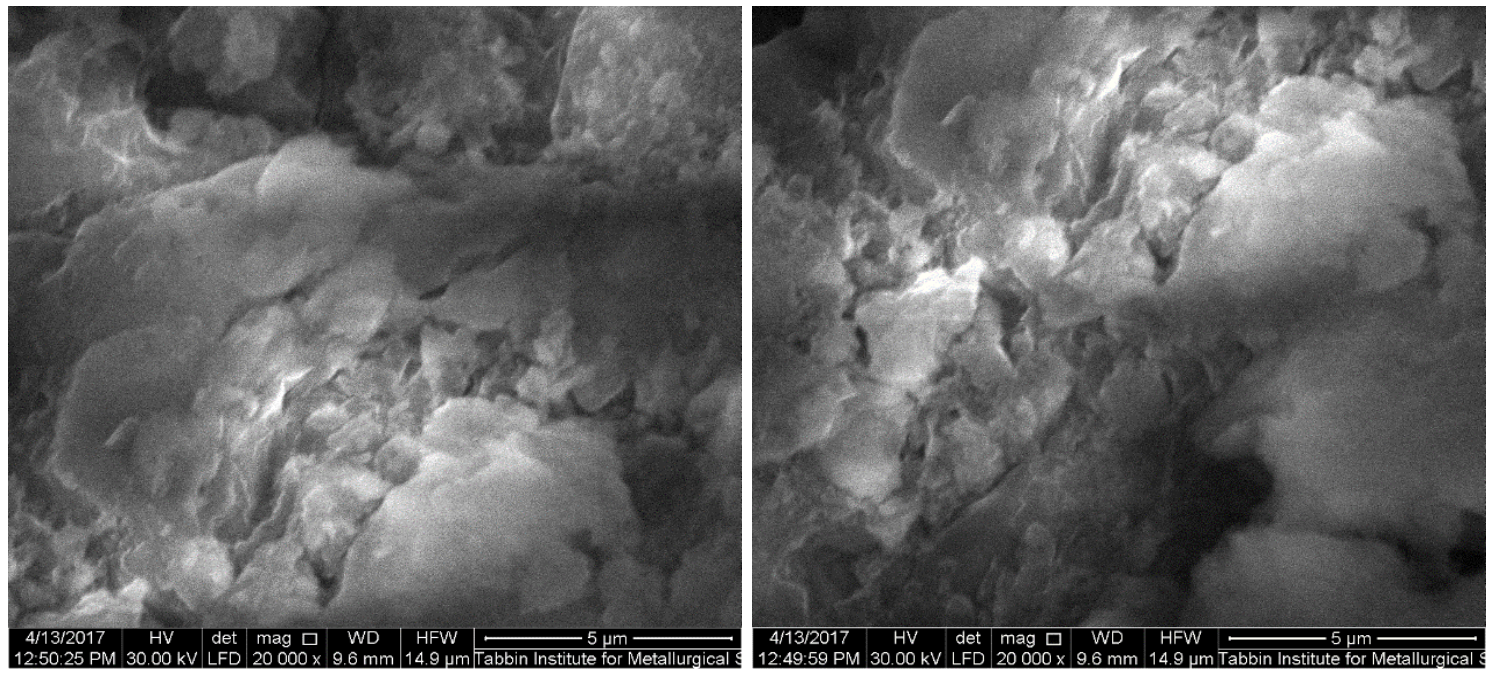

Fig. 10: SEM micrograph for the hardened OPC containing $5 \%$ alumina (A5) after 28 days of hydration. 


\section{Conclusions}

- The initial and final setting times of the blended cement pastes were reduced significantly when increasing the amount of partial substitution of alumina in OPC- A cement pastes.

- The optimum replacement of OPC by for the improvement of hydraulic properties of blended cement pastes is 5\%. The replacement of alumina in mix A5 causes a marked improvement of the microstructure of pastes.

- The DSC thermograms and XRD analysis for investigated cement pastes indicated the formation of nearly amorphous calcium silicates, calcium sulphoaluminate hydrates, calcium aluminate hydrates and portlandite.

- The SEM micrographs showed that the partial substitution of OPC by $5 \%$ alumina leads to denser structure as compared to the neat OPC paste.

\section{REFERENCES}

[1] Alessandra, M.; Alberto, B.; Chiara, G.; Tiziano, B. and Francesca, T.: "Metakaolin and fly ash alkali-activated mortars compared with cementitious mortars at the same strength class". Cement and concrete research, 88, pp. 198-210, (2016).

[2] Federica, L.; Elena, R. and Luca, B.: "A study on the applicability of the efficiency factor of supplementary cementitious materials to durability properties". Construction and building materials, 120, pp. 284-292, (2016).

[3] Sujitra, O.; Thanakorn, W.; Sirithan, J.; Shigetaka, W. and Parjaree, T.: "Effect of sodium hydroxide solution on the properties of geopolymer based on fly ash and aluminum waste blend". Suranaree J. Sci. Technol., 21, pp. 9-14, (2013).

[4] Hayrapetyan, S. S.; Mangasaryan, L. G.; Tovmasyan, M. R. and Khachatryan, H. G.: "Precipitation of aluminum hydroxide from sodium aluminate by treatment with formalin and preparation of aluminum oxide". Actachromatographica, No. 16, pp. 192-203, (2006).

[5] Heikal, M.; Ismail, M. N. and Ibrahim, N. S.: "Physico mechanical, microstructure characteristics and fire resistance of cement pastes containing $\mathrm{Al}_{2} \mathrm{O}_{3}$ nano-particles". Construction and building materials, 91, pp. 232-242, (2015).

[6] Nima, F.; Abang, A. A. and Ramazan, D.: "Characterization of high strength mortars with nano alumina at elevated temperatures". Cement and concrete research, 54, pp. 43-54, (2013).

[7] Nazari, A. and Riahi, S.: " $\mathrm{Al}_{2} \mathrm{O}_{3}$ nanoparticles in concrete and different curing media". Energy and buildings, 43, pp. 1480-1488, (2011).

[8] Kiachehr, B. and Niloofar, S.: "The effects of nano-silica and nano-alumina on frost resistance of normal concrete". Construction and building materials, 48, pp. 580-584, (2013).

[9] Erdem, E.; Gunay, M. E. and Donat, R.: "Hydration and mechanical properties of Portland cement containing eloxal waste from aluminum industry". Journal of materials processing technology, 136, pp. 35-38, (2003).

[10] Arefi, M. R.; Javeri, M. R. and Mollaahmadi, E.: "To study the effect of adding $\mathrm{Al}_{2} \mathrm{O}_{3}$ nanoparticle on the mechanical properties and microstructure of cement mortar". Life Sci. J., 61, pp. 3-7, (2011).

[11] Amin, M. S.; El-Gamal, S. M. A. and Hashem, F. S.: "Effect of addition of nanomagnetite on the hydration characteristics of hardened Portland cement and high slag cement pastes". J. therm. anal. calorim., 125, pp. 3-9, (2013). 
[12] Nazari, A.; Riahi, S.; Shamekhi, S. and Fand, K. A.: "Influence of $\mathrm{Al}_{2} \mathrm{O}_{3}$ nanoparticles on the compressive strength and workability of blended concrete". J. Am. Sci., 6, pp. 6-9, (2010).

[13] El-Diadamony, H.; Amer, A. A.; Sokkary, T. and El-Hoseny, S.: "Hydration and characteristics of metakaolin pozzolanic cement pastes". HBRC Journal, (2016).

[14] Abo-El-Enein, S. A.; Amin, M. S.; El-Hosiny, F. I.; Hanafi, S.; ElSokkary, T. M. and Hazem, M. M.: "Pozzolanic and hydraulic activity of nano-metakaolin". HBRC Journal, 10, pp. 64-72, (2014).

[15] Egyptian specification, the standard methods for the chemical analysis, (2010).

[16] Li, Y. S.; Lima, D. S.; Chunb, B. S. and Ryou, J. S.: "Characterization of a sodium aluminate $\left(\mathrm{NaAlO}_{2}\right)$-based accelerator made via a tablet processing method". J. Ceram. Process Res., 14 (1), pp. 87-91, (2013).

[17] Han, J.; Wang, K.; Shi, J. and Wang, Y.: "Influence of sodium aluminate on cement hydration and concrete properties". Construction and building materials, 64, pp. 342349, (2014).

[18] Abo-El-Enein, S. A.; Abbas, R. and El-Sayed, E.: "Properties and durability of metakaolin blended cements". Mater. de constr., 60, pp. 21-35, (2010).

[19] Mlinarik, L. and Katalin, K.: "Impact of metakaolin - a new supplementary material on the hydration mechanism of cements". Acta technical napocensis, civil engineering and architecture, 56, pp. 100-110, (2013).

[20] Frias, M. and Cabrera, J.: "The influence of MK on the reaction kinetics in MK/ lime and MK- blended cement systems at $20^{\circ} \mathrm{C} "$. Cem. conc. res. 31, pp. 519-527, (2001). 